\title{
Biochemical and Immunological Markers for the Early Diagnosis of Neonatal Septicaemia
}

\author{
Nesa $\mathrm{A}^{1^{*}}$, Yesmin $\mathrm{F}^{2}$, Muttalib $\mathrm{MA}^{2}$ \\ ${ }^{1}$ Department of Laboratory Medicine, BIRDEM General Hospital, Dhaka, Bangladesh; ${ }^{2}$ Department of \\ Biochemistry and Molecular Biology, BIRDEM General Hospital, Dhaka, Bangladesh
}

\begin{abstract}
Background: Neonatal sepsis is a life-threatening condition with high mortality and morbidity throughout the world.

Objective: This study evaluated the diagnostic role of serum procalcitonin (PCT), interleukin-6 (IL-6), tumor necrosis factor- $\alpha(\mathrm{TNF}-\alpha)$ and $\mathrm{C}$-reactive protein (CRP) in the early diagnosis of neonatal sepsis.

Methods: This cross-sectional study was conducted among neonates admitted to the special baby care unit (SCABU) of BIRDEM General Hospital, Dhaka, from November 2018 to April 2019. According to selection criteria, 90 clinically suspected cases of neonatal sepsis were selected and categorised into confirmed, probable, and no sepsis groups based on CRP, white cell count, platelet count, and blood culture results. Serum PCT, IL6 , and tumor necrosis factor (TNF- $\alpha$ ) were estimated in all cases by standard laboratory methods.

Results: Serum PCT, IL-6, CRP, and TNF- $\alpha$ were significantly higher in confirmed and probable sepsis groups in comparison to no sepsis group. Among the studied biomarkers, serum PCT was found most sensitive (95\% sensitivity), and serum IL-6 was found most specific biomarkers (65.7\% specificity) than CRP and TNF- $\alpha$ for the diagnosis of neonatal septicaemia. Though the accuracy of both PCT and IL-6 was found equal (70\%), but the positive predictive value (PPV) and negative predictive value (NPV) of serum PCT were higher than IL-6.
\end{abstract}

Conclusion: Both serum PCT and IL-6 are more sensitive and specific markers than CRP and TNF- $\alpha$ in the diagnosis of neonatal sepsis. Moreover, serum PCT is more useful than IL-6.

Keywords: Neonatal sepsis, Procalcitonin, Interleukin-6(IL-6), Tumor necrosis factor (TNF- $\alpha$ )

\section{Introduction}

Neonatal sepsis (NS) is a major cause of mortality and morbidity in newborn, and it is recognized as a global public health challenge. ${ }^{1,2}$ World Health Organization (WHO) estimates that 1 million deaths per year occur due to neonatal sepsis, and $42 \%$ of these deaths occur in the first week of life. ${ }^{3,4}$ Incidence of NS in south Asia is 4-10 times higher than that of developed countries. ${ }^{5}$ United Nations Inter-Agency group for child mortality estimation showed that in 2015 neonatal mortality rate (NMR) of Bangladesh was 23 deaths per 1000 live births and among them, $19.9 \%$ deaths occurred due to neonatal sepsis. ${ }^{6}$ Blood culture is the gold standard test for the diagnosis of neonatal sepsis. ${ }^{7}$ But it is a time-consuming method (take at least 24 - 48 hours) and often gives a false negative result. ${ }^{8}$ Therefore,

*Correspondence: Dr. Ayatun Nesa, Department of Laboratory Medicine, BIRDEM General Hospital, Dhaka, Bangladesh;

e-mail:dipa2801@yahoo.com,ORCID:0000-0002-2825-0314 the diagnosis of sepsis is usually based on clinical assessment, risk factors evaluation, and detection of other laboratory markers. During recent days acute phase proteins, pro-inflammatory cytokines, adhesion molecules, cell surface markers, and chemokines along with other conventional markers are being helpful to diagnose neonatal sepsis. ${ }^{9-11}$ Worldwide several studies reported that procalcitonin (PCT), interleukin-6 (IL-6), tumor necrosis factor- $\alpha$ (TNF- $\alpha$ ) and $\mathrm{C}$ reactive protein (CRP) are the sensitive markers for diagnosis of neonatal sepsis. ${ }^{9,12-14}$

CRP is an acute-phase protein and one of the most frequently used laboratory tests for the diagnosis of neonatal sepsis, but it takes 10-12 hours to change significantly after onset of infection. ${ }^{15} \mathrm{CRP}$ is a less sensitive marker during the early phase of sepsis ${ }^{15}$ but could be a helpful prognostic marker for lateonset neonatal sepsis. ${ }^{16}$ Procalcitonin (PCT),another acute-phase reactant, is released 
from nearly all tissues and increased up-to a thousand-fold in the host in response to cytokines and bacterial products without increasing calcitonin. ${ }^{17}$ Serum concentration of PCT begins to rise 4 hours after exposure to bacterial endotoxin, peaks at 6-8 hours and remains elevated for at least 24 hours and serum concentration is not affected by gestational age. ${ }^{15}$ Serum PCT was found significantly higher in proven versus probable sepsis group $(p<0.05) .{ }^{16}$ In a meta-analysis of 22 studies that evaluated the PCT test for the diagnosis of early onset sepsis at different time points (at birth, 0-12 hours, 12-24 hours, 12-24 hours and 2448 hours) and low onset sepsis, all showed moderate accuracy. ${ }^{18}$ Interleukin-6 (IL-6) is the recently studied cytokine in neonatal sepsis, synthesized by mononuclear phagocytes, endothelial cells, fibroblasts, and the decidua, chorion, amnion, and trophoblast cells, soon after stimulation by microbial products that show the early response to infection, preceding the increase in CRP. The release of IL-6 starts 4-6 hours after bacterial stimulation, and it peaks at 36 hours after infection but has a very short half-life, approximately 100 minutes. ${ }^{19}$ A study by Noor et al, 2008, in Bangladesh reported that IL-6 had 55.6\% sensitivity and $83.3 \%$ specificity in the diagnosis of neonatal sepsis. ${ }^{20} \mathrm{TNF}-\alpha$ is a pro-inflammatory cytokine also increased in patients with severe sepsis or septic shock. $^{21,22}$ In particular, TNF- $\alpha$ showed higher accuracy for the diagnosis of NS in low onset neonatal sepsis (LONS). ${ }^{23}$

Although several literature reviews showed serum PCT, IL-6, TNF- $\alpha$ and CRP are the early sensitive markers, but none of these laboratory sepsis markers have $100 \%$ sensitivity and specificity, and their results are conflicting. ${ }^{9,12,14}$ There are limited studies regarding these biomarkers in early diagnosis of neonatal sepsis were done in Bangladesh. So, this study was undertaken to assess the diagnostic value of different biomarkers (serum procalcitonin, interleukin-6, TNF- $\alpha$ and C-reactive protein) as early markers of neonatal sepsis and to find the most useful marker among them.

\section{Materials and Methods}

This cross-sectional study was carried out in the Department of Laboratory Medicine, BIRDEM General Hospital-2, during the period of Nov 2018 to April 2019. According to the inclusion and exclusion criteria, a total of 90 neonates were selected for the study from the Special Baby Care Unit (SCABU), BIRDEM General Hospital-2, Dhaka. Inclusion criteria were neonates having at least three clinical signs and symptoms of sepsis (fever or hypothermia, lethargy, poor feeding, reduced movements, reduced sucking, seizure, apnea / tachypnea, cyanosis, respiratory distress or need for mechanical ventilation, bradycardia/ tachycardia, hypotension or hypoperfusion, abdominal distension, jaundice, dehydration, chest indrawing, hypoglycemia and grunting). ${ }^{12,14,24}$ Neonates having any congenital malformation, TORCH infections, undergone any surgical procedure, or received antibiotics were excluded from the study.

After taking informed written consent from their guardians a structured questionnaire was filled up for each patient, including maternal obstetrical history, neonatal birth history, and signs and symptoms of sepsis. Cases were classified into 3 groups - confirmed sepsis, probable sepsis, and no sepsis groups. ${ }^{11,13}$ Group-1: Confirmed sepsis $(n=20)$ (subjects had $\geq 3$ sepsis-related signs and symptoms and blood culture positive); Group-2: Probable sepsis $(n=29)$ [subjects had $\geq 3$ sepsisrelated signs and symptom, blood culture-negative but positive sepsis screen which was defined by the presence of at least 2 altered sepsis-related blood tests including positive CRP, leukocytosis or leukopenia, thrombocytopenia, and low absolute neutrophil count; $\left.{ }^{25,26,27}\right]$; Group-3: No sepsis ( $\left.n=41\right)$ ( $\geq 3$ sepsis-related signs and symptoms but blood culture-negative and negative sepsis screen defined by the presence of less than 2 altered blood screening parameters).

With all aseptic precautions, $3.5 \mathrm{ml}$ blood was collected by vein puncture from each study subject. Among that, $1 \mathrm{ml}$ blood was delivered to EDTA tube for estimation of complete blood count $(\mathrm{CBC})$ and $1 \mathrm{ml}$ blood was delivered in blood culture tube containing sodium polyanethol sulfonate (SPS) for blood culture. Remaining $1.5 \mathrm{ml}$ blood was delivered to a plain test tube and allowed to clot for $30 \mathrm{~min}$ at $37^{\circ} \mathrm{C}$ before centrifugation for $15 \mathrm{~min}$ at $3000 \mathrm{rpm}$ for separation of serum. Separated serum were aliquoted into $1 \mathrm{ml}$ cryo-tubes and part of the sera 
was used for CRP analysis immediately at all sampling time and remainder stored at $-80^{\circ} \mathrm{C}$ until the time of estimation of serum PCT, IL-6 and TNF- $\alpha$. Serum procalcitonin (PCT) was measured by enzyme linked immunosorbent assay (ELISA) based on the sandwich principal for the quantitative measurement of human procalcitonin (Human Procalcitonin ELISA, Biovendor, Brno, Czech Republic). Quantitative measurement of serum interleukin-6 (IL-6) was done by enzyme linked immunosorbent assay (ELISA) (Thermo Fisher Scientific Invitrogen IL-6 Human ELISA Kit, KAC1261), and serum TNF- $\alpha$ were assessed by a solid phase enzyme amplified sensitivity immunoassay performed on microtiterplate (DRG TNF- $\alpha$ ELISA, EIA-4641). Serum C-reactive protein (CRP) was determined by Atlas $\mathrm{C}$ reactive Protein (CRP)latex reagent kit. Blood culture was evaluated by the lytic centrifugation method, and Complete blood count (CBC) was assessed by Sysmex XN-1000 haematology auto-analyser. Statistical analysis of the data was performed with the help of software SPSS, version 20. For comparison of characteristics, minimum, maximum, mean, and standard deviation of the different variables were determined. One-way ANOVA test was done to compare the means of the variables in between three groups. Diagnostic efficacy was defined as sensitivity, specificity, positive predictive value (PPV), negative predictive value (NPV), and accuracy. Results were presented as percentage $(\%)$, and receiver operating characteristic (ROC) curves were plotted for comparison efficiency of different biochemical parameters in the diagnosis of neonatal sepsis. All statistical tests were considered significant at the level of $\leq 5 \%$.

Ethical consideration: Prior to the commencement of the study, the research protocol was approved by the National Ethics Committee of the Bangladesh Medical Research Council (BMRC), Dhaka and informed written consent was taken from each parent of the study subjects.

\section{Results}

The study included a total of 90 cases who met the inclusion criteria. Cases were classified into 3 groups - confirmed sepsis, probable sepsis, and no sepsis. Frequency distribution of three groups in the total study subjects showed, confirmed sepsis contributed to $22.2 \%$, probable sepsis for $32.2 \%$, and no sepsis for $45.6 \%$ (figure 1 ).

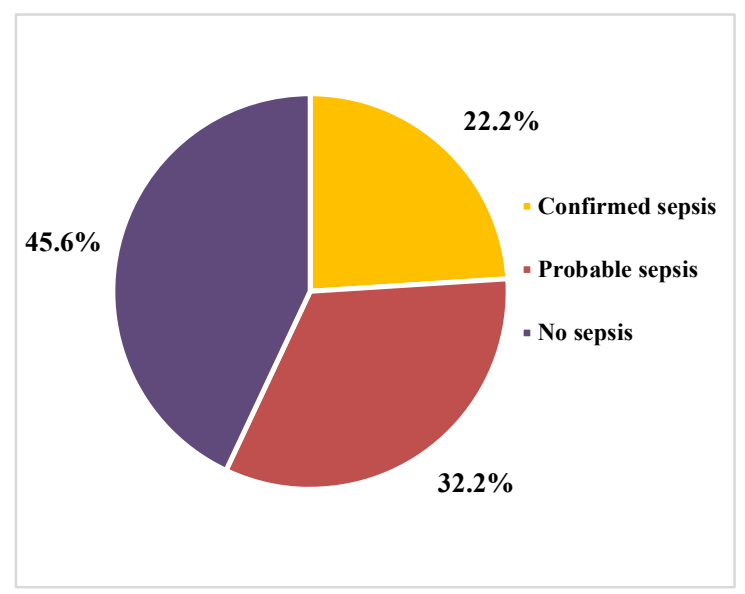

Figure 1: Distribution of three groups $(\mathrm{n}=90)$

The mean age at work-up in confirmed sepsis, probable sepsis, and no sepsis groups were found $3.70 \pm 3.03,2.76 \pm 2.82 \& 3.63 \pm 3.34$ days, respectively, and there were no significant differences observed (table I). In this study, most of the cases were of low birth weight (55.6\%) (table II).

Table I: Comparison of age at work-up, birth weight, gestational age and head circumference in between three groups (confirmed sepsis, probable sepsis and no sepsis)

\begin{tabular}{|c|c|c|c|c|}
\hline Variables & $\begin{array}{c}\text { Confirmed } \\
\text { sepsis } \\
(\mathbf{n}=\mathbf{2 0})\end{array}$ & $\begin{array}{c}\text { Probable } \\
\text { sepsis } \\
(n=29)\end{array}$ & $\begin{array}{c}\text { No sepsis } \\
(n=41)\end{array}$ & $\begin{array}{c}p \\
\text { value }\end{array}$ \\
\hline $\begin{array}{l}\text { Age at work- } \\
\text { up (day) }\end{array}$ & $3.70 \pm 3.03$ & $2.76 \pm 2.82$ & $3.63 \pm 3.34$ & $\begin{array}{c}0.444^{\mathrm{n}} \\
\mathrm{s}\end{array}$ \\
\hline $\begin{array}{l}\text { Birth weight } \\
\text { (kg) }\end{array}$ & $2.32 \pm 0.51$ & $2.41 \pm 0.56$ & $2.38 \pm 0.44$ & $\underset{s}{0.837^{\mathrm{n}}}$ \\
\hline $\begin{array}{l}\text { Gestational } \\
\text { age (week) }\end{array}$ & $35.10 \pm 1.74$ & $35.69 \pm 2.04$ & $35.37 \pm 2.13$ & $\underset{s}{0.595^{\mathrm{n}}}$ \\
\hline $\begin{array}{l}\text { Head } \\
\text { circumferenc } \\
\text { e (cm) }\end{array}$ & $32.38 \pm 1.97$ & $32.23 \pm 2.09$ & $32.89 \pm 1.65$ & $\underset{s}{0.315^{\mathrm{n}}}$ \\
\hline
\end{tabular}

Results are expressed in Mean $\pm \mathrm{SD}$; Statistical analysis was done by ANOVA test; ns $=$ not significant; $p$ value $<0.05$ was considered as level of significance.

The mean birth weight in confirmed sepsis, probable sepsis, and no sepsis groups was found $2.32 \pm 0.51$, $2.41 \pm 0.56 \& 2.38 \pm 0.44 \mathrm{~kg}$, respectively, and here also no significant differences were observed in between the groups (table I). Most of the study subjects were found preterm delivered $(60.0 \%)$ (table II). The mean gestational ages in confirmed sepsis, probable sepsis, and no sepsis groups were found $35.10 \pm 1.74$, $35.69 \pm 2.04 \& 35.37 \pm 2.13$ weeks, respectively and no significant differences were observed between the groups (table I). Regarding head circumference of the 
study subjects, no significant differences were again observed between the groups, and the mean head circumference in confirmed sepsis, probable sepsis, and no sepsis groups was found $32.38 \pm 1.97$, $32.23 \pm 2.09$ and $32.89 \pm 1.65 \mathrm{~cm}$ respectively (table I).

Table II: Demographic and obstetric information of the study subjects $(\mathrm{n}=90)$

\begin{tabular}{lcc}
\hline Variables & Frequency & $\begin{array}{c}\text { Percentage } \\
(\%)\end{array}$ \\
\hline Age: & & \\
$\leq 3$ days (EONS) & 57 & 63.3 \\
$>3$ days (LONS) & 33 & 36.7 \\
Gender & & \\
$\quad$ Male & 48 & 53.3 \\
Female & 42 & 46.7 \\
Gestational age & & \\
$\quad$ Pre-term $(<37$ & 54 & 60.0 \\
weeks) & 36 & 40.0 \\
$\quad$ Term ( $\geq 37$ weeks) & & \\
Mode of delivery & & \\
LUCS & 51 & 56.7 \\
$\quad$ NVD & 39 & 43.3 \\
Birth weight & & \\
LBW $(<2.5 \mathrm{~kg})$ & 50 & 55.6 \\
$\quad$ Normal birth & 40 & 44.4 \\
$\quad$ weight $(\geq 2.5 \mathrm{~kg})$ & & \\
Place of residence & & \\
$\quad$ Urban & 75 & 83.3 \\
Sub-urban & 10 & 11.1 \\
$\quad$ Rural & 05 & 5.6 \\
\hline
\end{tabular}

Among them, early onset neonatal sepsis (EONS) contributed for $63.3 \%$ and low onset neonatal sepsis (LONS) for $36.7 \%$. 56.7\% cases were delivered by LUCS and $43.3 \%$ by NVD. Among them $53.3 \%$ were male and $46.7 \%$ were female. $60.0 \%$ were preterm babies (gestational age $<37$ weeks) and $40.0 \%$ were term babies (gestational age $\geq 37$ weeks). $55.6 \%$ were born with LBW (birth weight $<2.5 \mathrm{~kg}$ ) and $44.4 \%$ were born with normal birth weight (birth weight $\geq 2.5 \mathrm{~kg}$ ).

Table III: Comparison of serum PCT, IL-6, CRP and TNF$\alpha$ level in between three groups in study subjects $(n=90)$

\begin{tabular}{ccccc}
\hline Variables & $\begin{array}{c}\text { Confirmed } \\
\text { sepsis(n=2 } \\
\mathbf{0})\end{array}$ & $\begin{array}{c}\text { Probable } \\
\text { sepsis(n=2 } \\
\mathbf{9}\end{array}$ & $\begin{array}{c}\text { No } \\
\text { sepsis } \\
(\mathbf{n}=\mathbf{4 1})\end{array}$ & $\begin{array}{c}\boldsymbol{p} \\
\text { value }\end{array}$ \\
\hline PCT & $1.73 \pm 0.88$ & $1.02 \pm 0.55$ & $0.14 \pm 0.1$ & $<0.00$ \\
$(\mathbf{n g} / \mathbf{m l})$ & & & 4 & 1 \\
$\mathbf{I L - 6}$ & $61.63 \pm 42.85$ & & $12.48 \pm 5.4$ & $<0.00$ \\
$(\mathbf{p g} / \mathbf{m l})$ & & $53.48 \pm 43.75$ & 5 & 1 \\
CRP & $16.61 \pm 15.38$ & $13.75 \pm 8.79$ & $0.80 \pm 0.5$ & $<0.00$ \\
$\mathbf{( m g / L )}$ & & & 6 & 1 \\
$\mathbf{T N F - \alpha}$ & $58.84 \pm 47.01$ & $29.37 \pm 21.62$ & $9.51 \pm 5.4$ & $<0.00$ \\
$(\mathbf{p g} / \mathbf{m l})$ & & & 8 & 1 \\
\hline
\end{tabular}

Results are expressed in Mean $\pm \mathrm{SD}$; Statistical analysis was done by ANOVA test; $p$ value $<0.05$ was considered as level of significance.

All the biochemical variables were found significantly higher $(p<0.001)$ in confirmed and probable sepsis groups in comparison to no sepsis group. The mean PCT, IL-6, CRP and TNF- $\alpha$ level in confirmed sepsis group were $1.73 \pm 0.88 \mathrm{ng} / \mathrm{ml}$, $61.63 \pm 42.85 \quad \mathrm{pg} / \mathrm{ml}, \quad 16.61 \pm 15.38 \quad \mathrm{mg} / \mathrm{L} \quad \&$ $58.84 \pm 47.01(\mathrm{pg} / \mathrm{ml})$ respectively. The mean PCT, IL-6, CRP and TNF- $\alpha$ level in probable sepsis group were $1.02 \pm 0.55 \mathrm{ng} / \mathrm{ml}, \quad 53.48 \pm 43.75 \mathrm{pg} / \mathrm{ml}$, $13.75 \pm 8.79 \quad \mathrm{mg} / \mathrm{L} \quad \& \quad 29.37 \pm 21.62 \quad(\mathrm{pg} / \mathrm{ml})$ respectively. And the mean PCT, IL-6, CRP and TNF- $\alpha$ level in no sepsis group were $0.14 \pm 0.14$ $\mathrm{ng} / \mathrm{ml}, \quad 12.48 \pm 5.45 \mathrm{pg} / \mathrm{ml}, \quad 0.80 \pm 0.56 \mathrm{mg} / \mathrm{L} \quad \&$ $9.51 \pm 5.48(\mathrm{pg} / \mathrm{ml})$ respectively (table III).

The diagnostic role of serum PCT, IL-6, CRP, and TNF- $\alpha$ in the diagnosis of neonatal septicaemia had been observed in this study (table IV).

Table IV: Diagnostic role of serum PCT, IL-6, CRP and TNF- $\alpha(n=90)$

\begin{tabular}{lllll}
\hline $\begin{array}{l}\text { Diagnostic } \\
\text { tests }\end{array}$ & PCT & IL-6 & CRP & $\begin{array}{l}\text { TNF- } \\
\boldsymbol{\alpha}\end{array}$ \\
\hline Sensitivity(\%) & 95.0 & 85.0 & 80.0 & 75.0 \\
Specificity(\%) & 62.9 & 65.7 & 58.6 & 62.7 \\
PPV(\%) & 42.2 & 41.5 & 35.6 & 36.6 \\
NPV(\%) & 97.8 & 93.9 & 91.1 & 89.8 \\
Accuracy(\%) & 70.0 & 70.0 & 63.3 & 65.6 \\
\hline
\end{tabular}

The sensitivity of serum PCT was found higher than that of serum IL-6, CRP, and TNF- $\alpha$ (95\% vs. $85 \%$ vs. $80 \%$ vs. $75 \%$ ). On the other hand, the specificity of serum IL- 6 was found higher than that of PCT, CRP, and TNF- $\alpha(65.7 \%$ vs. $62.9 \%$ vs. $58.6 \%$ vs. $62.7 \%$ ). Both positive predictive value (PPV) and negative predictive value (NPV) of PCT were found higher than IL-6, CRP and TNF- $\alpha$ ( $42.2 \%$ vs. $41.5 \%$ vs. $35.6 \%$ vs. $36.6 \%$ and $97.8 \%$ vs. $93.9 \%$ vs. $91.1 \%$ vs. $89.8 \%$ respectively). Accuracy was found equal for both PCT and IL-6 (70\%). Accuracy was found $63.3 \%$ for CRP and $65.6 \%$ for TNF- $\alpha$. So both PCT and IL- 6 were found more sensitive and specific marker than CRP and TNF- $\alpha$ in the diagnosis of neonatal septicaemia.

Receiver operator characteristics (ROC) curves for serum PCT, IL-6, CRP and TNF- $\alpha$ in the study subjects $(n=90)$, found that area under the curves 
(AUC) for all the variables were highly significant, but AUC for serum PCT was higher than IL-6, CRP, and TNF- $\alpha(0.880$ vs. 0.793 vs. 0.781 vs. 0.781 respectively) (figure 2).

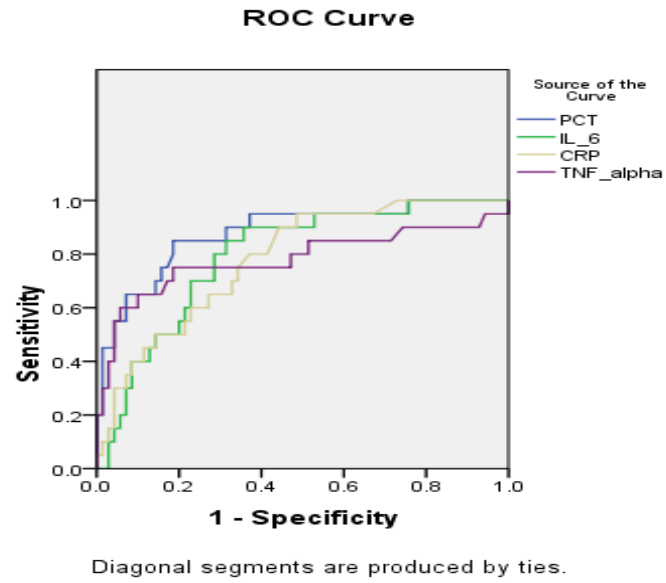

Figure 2: ROC curves for serum PCT, IL-6, CRP and TNF- $\alpha$ level in the study subjects

\section{Discussion}

Neonatal sepsis is a major cause of neonatal morbidity and mortality owing to the late onset of symptoms and non-specific clinical presentations. Early diagnosis of neonatal sepsis is essential prerequisite to improve survival and to improve therapeutic outcome. As such, there is much interest in developing rapid and sensitive diagnostic assays that can effectively predict and identify patients who are at risk of infection.

This study assessed the diagnostic role of serum procalcitonin (PCT), interleukin-6 (IL-6), Creactive protein (CRP) and tumor necrosis factoralpha (TNF- $\alpha$ ) as early markers of neonatal sepsis. A total of 90 study subjects were included and classified into 3 groups- confirmed sepsis $(\mathrm{n}=20)$, probable sepsis $(n=29)$, and no sepsis $(n=41)$ group, according to blood culture report and blood screening parameters. Distribution of 3 groups in this study were consistent with other previous studies done in Saudi Arabia and Austria. ${ }^{13,27}$

Comparison of age at work-up (day), birth weight $(\mathrm{kg})$, and gestational age during delivery (week) and head circumference $(\mathrm{cm})$ in between three groups were done in this study, but there were no significant differences found. In a previous study done by Khassawneh et al also reported, no significant difference of these variables in between three groups which was quite similar to our study. ${ }^{28}$

Comparison of biochemical and immunological variables (PCT, IL-6, CRP, and TNF- $\alpha$ ) in between three groups, found that all the variables were significantly higher in confirmed and probable sepsis groups than no sepsis group. Similar results were seen in some other previous studies. ${ }^{13,25,27,28}$ In this study, diagnostic tests of biomarkers (PCT, IL-6, CRP, and TNF- $\alpha$ ) revealed that both serum PCT and IL-6 were more sensitive, specific, and accurate than serum CRP and TNF- $\alpha$. Similarly, Park et al found a high sensitivity of serum PCT in their study. ${ }^{25}$ Khassawnehet al and Kuster et al also reported a high sensitivity of IL-6 in the diagnosis of neonatal sepsis, which was consistent with our study ${ }^{28,29}$ But Al-zahrani et al reported high sensitivity of CRP in the diagnosis of neonatal sepsis, which was quite dissimilar with our study. ${ }^{13}$ In a study by Kocabas et al reported the sensitivity \& specificity of TNF- $\alpha$ was $100 \%$ and $96.6 \%$ in the diagnosis of neonatal sepsis, which was also quite dissimilar with our study. ${ }^{10}$

Receiver operator characteristic (ROC) curves were drawn for serum PCT, IL-6, CRP, and TNF- $\alpha$ in our study. Areas under the curve (AUC) for serum PCT, IL-6, CRP, and TNF- $\alpha$ were $0.880,0.793,0.781,0.781$, and all of them were highly significant. Serum PCT was found more useful marker than IL-6, CRP, and TNF- $\alpha$ in the diagnosis of neonatal sepsis. In the previous study by Park et al. and Khassawneh et al also reported, AUC for serum PCT were 0.803 and 0.708 respectively, which were similar with this study. ${ }^{25,} 28$

\section{Conclusion}

This study revealed that both procalcitonin (PCT) and interlukin-6 (IL-6) are more sensitive and specific biomarkers than $\mathrm{C}$ reactive protein (CRP) and tumor necrosis factor $-\alpha(\mathrm{TNF}-\alpha)$ for the early diagnosis of neonatal septicaemia. Moreover, serum PCT is a more useful marker than IL-6.

\section{Acknowledgments}

The authors are grateful to the Bangladesh Medical and Research Council (BMRC), Bangladesh, for their financial assistance. The authors are also 
thankful to the technical staffs of the special baby care unit (SCABU) and department of Laboratory Medicine of BIRDEM-2 for their cooperation and technical supports during research work. Authors are grateful to the study subjects and their parents who participated willingly in this research.

Conflict of Interest: There was no conflict of interest

\section{Funding: Bangladesh Medical Research Council (BMRC)}

Ethical approval: National Research Ethics Committee of the BMRC

Submitted: $12^{\text {th }}$ December, 2019

Final revision received: $26^{\text {th }}$ July, 2020

Accepted:30 $30^{\text {th }}$ July, 2020

Published: $1^{\text {st }}$ August, 2020

\section{Reference}

1. Dima M, Lacob D, Marginean O, Lacob ER. New emerging biological markers of neonatal sepsis. J Res Med Sci.2017; 22:65.

Doi: 10.4103\%2Fjrms.JRMS_912_15.

2. Mally P, Xu J, Hendricks-Munoz K. Biomarkers for neonatal sepsis: recent developments. Dovepress. 2014; 157-168.

DOI: $10.2147 /$ RRN.S48316.

3. Edmond $\mathrm{K}$ and Zaidi A. New approaches to preventing, diagnosing and treating neonatal sepsis. PLoS Medicine.2010; 7:e1000213.

DOI: 10.1371/journal.pmed. 1000213.

4. Lawn J, Cousens S and Zupan J. 4 million neonatal deaths: When? Where? Why? The Lancet. 2005; 365: 891-900.

DOI: $10.1016 / \mathrm{s} 0140-6736(05) 71048-5$

5. Chaurasia S, Sivanandan S, Agarwal R, Ellis S. Neonatal sepsis in South Asia: huge burden and sprialling antimicrobial resistance. BMJ. 2019; 364: k5314.

DOI: $10.1136 / \mathrm{bmj} . \mathrm{k} 5314$

6. Maternal and newborn Health Disparities in Bangladesh.

https://www.google.com/url?sa=t\&rct=j\&q=\&esrc $=\mathrm{s} \&$ source $=$ web $\& \mathrm{~cd}=\&$ ved $=2$ ahUKEwi5h bZoq7sAhVDOSsKHSyaBIMQFjAAegQIARAC\& url $=$ https $\% 3 \mathrm{~A} \% 2 \mathrm{~F} \% 2 \mathrm{Fdata}$.unicef.org $\% 2 \mathrm{Fwp}-$ content $\% 2$ Fuploads $\% 2$ Fcountry_profiles $\% 2 \mathrm{FBangl}$ adesh $\% 2$ Fcountry $\% 2520$ profile_BGD.pdf\&usg=A OvVaw1CWIES2RMN3K62n2Eu6heQ

7. Shane AL. Stoll BJ. Recent developments and current issues in the epidemiology, diagnosis and management of bacterial and fungal neonatal sepsis. American Journal of Perinatology. 2013; 30: 131-142. DOI: $10.1055 / \mathrm{s}-0032-1333413$.
8. Guibourdenche J, Bedu A, Petzold L, Marchand M, Mariani-Kurdjian P, Hurtaud-Roux M, Aujard Y,Porquet D. Biochemical markers of neonatal sepsis: value of procalcitonin in the emergency setting. Annals of Clinical Biochemistry. 2002; 39:2 130-135.

DOI: $10.1258 / 0004563021901874$

9. Chatterjee K, Mandal PK, Rahaman SR, Malathi R, Ray SK, Dutta A, Gupta CN. Raised IL-6 and Creactive protein in neonatal sepsis in Eastern India. International Journal of Contemporary Pediatrics.2017; 4:1590-1594.

DOI: $10.18203 / 2349-3291 . i j c p 20173124$.

10. Kocabas E, SarikciogluA, Aksary N, Seydaoglu G, Seyhun Y, Yaman A. Role of procalcitonin, Creactive protein, interleukin- 6 , interleukin- 8 and tumor necrosis factor- $\alpha$ in the diagnosis of neonatal sepsis. The Turkish Journal of Pediatrics. 2007; 49:17-20.PMID: 17479639.

11. Ballot DE, Perovic O, Galpin J, Cooper PA. Serum procalcitonin as an early marker of neonatal sepsis. South African Medical Journal. 2004; 94: 851-854.

12. Ganesan P, Shanmugam P, Sattar SB, Shankar SL. (Evaluation of IL-6, CRP and hs-CRP as early markers of neonatal sepsis. Journal of Clinical and Diagnostic Research. 2014; 10: 13-17.

DOI: $10.7860 \% 2 F J C D R \% 2 F 2016 \% 2 F 19214.7764$.

13. Al-Zahrani AK, Ghonaim MM, Hussein YM, Eed EM, Khalifa AS, Dorgham LS. Evaluation of recent methods versus conventional methods for diagnosis of early-onset neonatal sepsis. The Journal of Infection in Developing Countries. 2015;9: 388-393.

DOI: $10.3855 /$ jidc. 5950 .

14. Abdollahi A, Shoar S, Nayyeri F, Shariat M. Diagnostic value of simultaneous measurement of procalcitonin, interleukin-6 and hs-CRP in prediction of early-onset neonatal sepsis. Mediterranean Journal of Hematology and Infectious Diseases. 2012;4: e2012028.

DOI: $10.4084 \% 2 F M J H I D .2012 .028$.

15. Shah BA and Padbury JF. Neonatal sepsis: an old problem with new insights. Virulence. 2013;5:170-178.

DOI: $10.4161 /$ viru.26906.

16. Rashwan NI, Hassan MH, EL-Deen ZMM. Ahmed AE. Validity of biomarkers in screening for neonatal sepsis - A single center - hospital based study. Pediatrics \& Neonatology.2019; 60: 149-15. DOI: $10.1016 /$ j.pedneo.2018.05.001.

17. Muller B and Becker KL. Procalcitonin: how a hormone became a marker and mediator of sepsis. Swiss Medical Weekly. 2001; 131: 595-602.

18. Yu Z, Liu J, Sun Q, Qiu Y, Han S, Guo X. The accuracy of the procalcitonin test for the diagnosis of neonatal sepsis: A meta-analysis. Scandinavian Journal of Infectious Diseases. 2010; 42:723-33. DOI: $10.3109 / 00365548.2010 .489906$. 
19. Machado JR, Saove DF, Silva M, Menezes LV, Etchebehere RM, Monteiro M, Reis M, Correa R, Celes M. Neonatal sepsis and inflammatory mediators. Mediators of Inflammation. 2014; 1-10. DOI: $10.1155 / 2014 / 269681$

20. Noor MK, Shahidullah M, Rahman H, Mutanabbi M. Interleukin-6: A Sensitive Parameter for the Early Detection of Neonatal Sepsis. Bangabandhu Sheikh Mujib Medical University Journal. 2009; 1: 1-5. DOI: 10.3329/bsmmuj.v1i1.3687

21. Ganda IJ, Andriani Y, Lawang SA, Doud D. Initial serum level of TNF- $\alpha$ as an outcome predictor in pediatric patient with sepsis. Current Pediatric Research. 2018; 22:2.

22. Abbas A, Lichtman A, Pillai S. Cellular and Molecular Immunology. $8^{\text {th }}$ edn. WB Saunders Comp. 2015.

23. Bokun LV, Huang J, Yuan H, Yan W, Hu G, Wang J. Tumor Necrosis Factor- $\alpha$ as a Diagnostic Marker for Neonatal Sepsis: A Meta-Analysis The Scientific World Journal. 2014; 14.

DOI: $10.1155 / 2014 / 471463$

24. Vazzalwar R, Pina-Rodriques E, Puppala B, Krieger $\mathrm{P}$, Angst $\mathrm{D}$, Schweig L. Procalcitonin as a screening test for late-onset sepsis in preterm very low birth weight infants. Journal of Investigative Medicine. 2004; 25: 397-402.

DOI: $10.1038 /$ sj.jp. 7211296
25. Park IH, Lee SH, Yu ST, Oh YK. Serum procalcitonin as a diagnostic marker of neonatal sepsis. Korean Journal of Pediatrics. 2014; 57: 451456.

DOI: $10.3345 \% 2 F k j p .2014 .57 .10 .451$

26. Tripathi S, Malik GK. Neonatal sepsis: past, present and future; a review article. Internet Journal of Medical Update. 2010;5: 45-54.

DOI: $10.4314 /$ ijmu.v5i2.56163

27. Resch B, Gusenleitner W, Muller WD. Procalcitonin and interleukin-6 in the diagnosis of early-onset sepsis of the neonate. AtcaPaediatr.2003; 921: 243-245.

DOI: 10.1111/j.1651-2227.2003.tb00534.x

28. Khassawneh M, Hayajneh W, Kofahi H, Khader Y,Amarin Z, Daoud A. Diagnostic markers for neonatal sepsis: comparing C-reactive protein, interleukin-6 and immunoglobulin $M$. Scandinavian Journal of immunology. 2007; 65: 171-175.

DOI: $10.1111 / \mathrm{j} .1365-3083.2006 .01878 . x$

29. Kuster H, Weiss M, Willeitner A, Detlefsen S, Jeremias I, Zbojan J, Geiger R, Lipowsky G, Simbruner G. Interleukin-1 receptor antagonist and interleukin- 6 for early diagnosis of neonatal sepsis 2 days before clinical manifestation. The Lancet. 1998; 352: 1271-1277.

DOI:10.1016/S0140-6736(98)08148-3 